Research Article

Journal of Research and Review in Science, 72-79

Volume 5, December 2018

DOI: $10.36108 /$ jrslasu/8102/50(0190)

ORIGINAL RESEARCH

\title{
THERMODYNAMICS OF ADSORPTION OF FOOD COLOURS
}

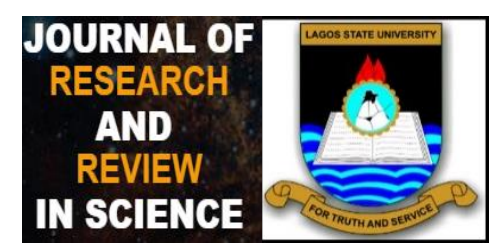

\section{Isaac Adebayo Akinbulu ${ }^{1}$, Babatunde Taofeek Ogunbayo ${ }^{2}$ and Adewale Kabir Ipadeola ${ }^{3}$}

\author{
${ }^{1}$ Department of Chemistry, Faculty of \\ Science, University of Lagos, Nigeria \\ ${ }^{2}$ Department of Chemistry, Faculty of \\ Science, University of Lagos, Nigeria \\ ${ }^{3}$ Department of Chemistry, Faculty of \\ Science, University of Lagos, Nigeria

\section{Correspondence} \\ Isaac Adebayo Akinbulu, Department of \\ Chemistry, Faculty of Science, University of \\ Lagos, Nigeria. \\ Email: iakinbulu@unilag.edu.ng
}

\section{Abstract:}

Thermodynamics of adsorption of two synthetic food colours, Tartrazine and Brilliant blue, was investigated. The adsorbent used was activated carbon, produced from saw dust waste. For each of the food colours, equilibrium studies were carried out at different temperatures ( $308 \mathrm{~K}, 318$ $\mathrm{K}, 328 \mathrm{~K}$ and $338 \mathrm{~K}$ ). The Langmuir adsorption model was employed for equilibrium studies. Amount of colour adsorbed per gram of adsorbent, at equilibrium, was influenced by molecular size of adsorbate and temperature. Adsorption at the tartrazine-adsorbent interface was exothermic, while that at the brilliant blue-adsorbent interface was endothermic. Adsorption of tartrazine was associated with a negative entropy change, while there was increased degree of disorderliness at the brilliant blue-adsorbent interface. Each of the adsorbate-adsorbent systems was associated with positive change in Gibbs free energy, within the range of temperature employed in this work.

To Keywords: Thermodynamics, Tartrazine, Brilliant blue, Activated carbon, Adsorbate-adsorbent interface 


\section{INTRODUCTION}

Food colours are any dyes, pigments or substances that add colours to food substances (foods, drugs and drinks). They are complex organic chemicals, which may exist as liquids, powders, gels and pastes. The quality of food colours is a measure of the acceptability of food products, which explains why food quality is often related to its colour. Certain food colours are usually identified with certain flavours [1], and the colour of food influences not only its perception of flavour, but also gives good attraction and quality for its consumption [2]. Also, food colours may be added to food products to make up for natural changes in colours, and loss of colours, resulting from exposure to light, extreme temperature, moisture and harsh storage conditions. Food colours may also be added for decorative purpose [3].The attraction for these organic chemical substances (synthetic food colours) can also be attributed to cost, stability and degree of brightness. They are often cheaper, more stable and brighter than most natural food colours.

However, it is important to note that the use of synthetic food colours can be associated with certain health consequences. The adverse effects of synthetic food colours on health of humans, and animals alike, overshadow the perceived importance and preference for these organic chemical substances. Such health hazards become more pronounced when these food colours are used in excess of their acceptable daily intake or tolerance levels. The fact that these organic chemical substances are not just pure chemicals is an added risk. They may contain some percent of impurities, which are present in the chemicals from which they are synthesized. Some of these contaminants, such as 4-aminobiphenyl, 4aminoazobenzene and benzidine, are supposed to be present at safely negligible levels in food colours, but have been found to be carcinogenic [4]. Another very disturbing scenario is the fact that, in most cases, the acceptable daily intake or tolerance levels for some synthetic food colours are not regularly updated, to be in tandem with the current health realities, by the relevant regulatory agencies. It has also been reported that the risk that synthetic food colours pose to children, who are particularly more sensitive to carcinogens and consume more food colours per unit of body weight than adults, was not effectively factored-in in the estimation of the tolerance levels for these organic chemicals [5]. Therefore, there is the need to design a cheap, but effective, means of removing these colours from food products, in case they are used in excess of recommended values, or precipitate adverse health effects.
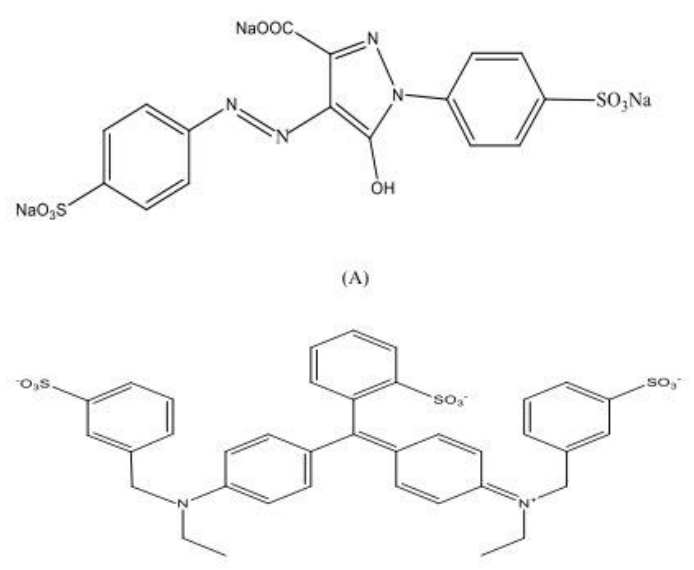

(B)

Fig. 1: Molecular structures of (A) Tartrazine and (B) Brilliant blue

This underscores the purpose of the current work, with particular emphasis on the thermodynamics of the adsorption process. In the current work, activated carbon was used for the adsorption of these synthetic food colours. The molecular structures of these colours (Brilliant blue and Tartrazine) are shown in Figure 1. Tartrazine (Trisodium-5-oxo-1-(4-sulphonatophenyl) hydrazono-3-pyrazolecarboxylate), Figure $1(\mathrm{~A})$, is a synthetic lemon yellow dye. It appears to cause the most allergic reactions of all the azo dyes. The harmful reactions associated with tartrazine include migraine, blurred vision and itching [6]. Brilliant blue (Ethyl-[4-[4[ethyl-[(3-sulphophenyl) methylidene]-1-cyclohexa-2, 5dienylidene]-[(3 sulphophenyl) methyl] azanium), Figure $1(B)$, has the capacity for inducing an allergic reaction in individuals with pre-existing moderate asthma [7].

The activated carbon used was produced from sawdust waste. The choice of saw dust was informed by the fact that, the cellulosic architecture of wood-based waste could give rise to activated carbon with a predominantly meso-macroporous structure, with higher proportion of mesoporous nature. Such structural network enhances the adsorption of relatively large molecular sized adsorbate, such as the synthetic food colours used in this work. Usually, all activated carbons contain micropores, mesopores and macropores within their structures, but the relative proportions vary considerably according to the raw material [8].

In the current work, thermodynamics parameters, such as change in Gibb's free energy $(\Delta G)$, enthalpy change $(\Delta H)$ and entropy change $(\Delta S)$, were determined, and their physical relevance explained. Investigation of the thermodynamics of the process was facilitated by equilibrium studies of the adsorption processes. The Langmuir adsorption isotherm model was employed for equilibrium study. This model has been used widely to describe the single-solute adsorption system. It is based on the assumption that adsorption is a type of chemical combination, between adsorbent and adsorbate. Essentially, this adsorption model predicts monolayer coverage [9]. In this model, the process of adsorption is a physical phenomenon or physiosorption, as there is significant interaction between adsorbate and adsorbent. This model assumed uniform energies of 
adsorbate in the plane of the surface of the adsorbent [10]. Theoretically, the adsorbent has a finite capacity for adsorption. Once an adsorbate molecule occupies a site, further adsorption cannot take place at the adsorptive site, suggesting monolayer coverage of the adsorbent. Adsorption continues until a monolayer of adsorbate is formed, and after the completion of adsorption, no more interaction between the adsorbent and adsorbent [11].

Mathematical representation of the Langmuir adsorption isotherm is expressed by equation 1

$q_{e}=\frac{q_{o} K_{L} C_{e}}{\left(1+K_{L} C_{e}\right)} \quad 1$

$q_{e}=$ amount of substance adsorbed at equilibrium, per

unit mass of activated carbon $(\mathrm{mg} / \mathrm{g})$,

$C_{e}=$ initial concentration of the adsorbate $(\mathrm{mg} / \mathrm{L})$

$K_{L}=$ Langmuir adsorption isotherm constant $(\mathrm{L} / \mathrm{mg})$

$q_{0}=$ adsorption capacity $(\mathrm{g} / \mathrm{mg})$

The linear form of equation 1 gives equation 2

$\frac{1}{q_{e}}=\frac{1}{q_{o}}+\frac{1}{K_{L} q_{o}} \times \frac{1}{C_{e}}$

A plot of $\frac{1}{q_{e}}$ versus $\frac{1}{c_{e}}$ gives a straight line. Values of $q_{0}$ and $K_{L}$ can be obtained from the intercept and slope of the plot respectively. In the current work, the Langmuir parameter, $K_{\mathrm{L}}$, was evaluated at different temperatures, from which the corresponding values of $\Delta G$ were obtained, using equation 3.

$\Delta G=-R T \ln K_{L}$

$\Delta G=$ change in Gibb's free energy

$R=$ molar gas constant

$T=$ absolute temperature

The change in Gibb's free energy can also be defined as shown in equation 4

$\Delta G=\Delta H-T \Delta S$

Substitution of equation 4 in equation 3 gives equation

5 , the Van't Hoff equation

$\ln K_{L}=\frac{\Delta S}{R}-\frac{\Delta H}{R T}$

The plot of $\ln K_{L}$ versus $\frac{1}{T}$ give a straight-line graph. Values of enthalpy change $(\Delta H)$ and entropy change $(\Delta S)$ were obtained from the slope and intercept of the plot respectively.

\section{MATERIAL AND METHODS}

\subsection{Materials}

Sodium hydroxide, potassium hydroxide, hydrochloric acid, synthetic food colours (tartrazine and brilliant blue) were purchased from Sigma Aldrich, while sawdust waste was obtained locally.

\subsection{Equipment}

Mechanical grinder, analytical balance, electric oven, electric furnace, thermostat magnetic stirrer, volumetric flask, glass rod, measuring cylinder, T80++ double beam UV-visible spectrophotometer and Mettler Toledo $\mathrm{pH}$ meter.

\subsection{Preparation of solutions}

\subsection{Hydrochloric acid}

$9.0 \mathrm{~cm}^{3}$ of concentrated hydrochloric acid (Specific gravity $=1.18 \mathrm{~g} / \mathrm{cm}^{3}$, purity= $36 \%$ ) were measured into $1000 \mathrm{ml}$ volumetric flask. The acid was diluted with distilled water to the $1000 \mathrm{ml}$ mark to give the desired concentration.

\subsection{Potassium hydroxide solution}

$84.0 \mathrm{~g}$ of potassium hydroxide pellets were weighed into a $1000 \mathrm{ml}$ volumetric flask, distilled water was added, and the resulting solution diluted to the $1000 \mathrm{ml}$ mark, to give the desired concentration.

\subsection{Sodium hydroxide solution}

$0.2 \mathrm{~g}$ of sodium hydroxide pellets were weighed into $1000 \mathrm{ml}$ volumetric flask, distilled water was added and the solution diluted to the $1000 \mathrm{ml}$ mark, to give the desired concentration.

\subsubsection{Test solutions of food colours}

Three synthetic food colours; tartrazine and brilliant blue of commercial purity, were used without further purification. The stock solution $(1000 \mathrm{ml})$ of each of the food colours was prepared by dissolving accurately weighed amount of the food colour in required volume of distilled water.

\subsubsection{Test solution of Tartrazine}

The molecular formula and molar mass of tartrazine are $\mathrm{C}_{16} \mathrm{H}_{9} \mathrm{~N}_{4} \mathrm{Na}_{3} \mathrm{O}_{9} \mathrm{~S}_{2}$ and $534.36 \mathrm{~g} \mathrm{~mol}^{-1}$ respectively. It has its maximum absorption at $426 \mathrm{~nm}$. A stock solution of tartrazine solution, $1000 \mathrm{mg} / \mathrm{L}(1.87 \mathrm{mM})$, was obtained by weighing $1.0 \mathrm{~g}$ of tartrazine powder in a volumetric flask. Distilled water was added and the solution diluted to the $1000 \mathrm{ml}$ mark. Test solutions were prepared by diluting the stock solution to the desired concentration.

\subsubsection{Test solution of Brilliant blue}

The molecular formula and molar mass of brilliant blue are $\mathrm{C}_{37} \mathrm{H}_{34} \mathrm{~N}_{2} \mathrm{Na}_{2} \mathrm{O}_{9} \mathrm{~S}_{3}$ and $792.85 \mathrm{~g} \mathrm{~mol}^{-1}$ respectively. Its maximum absorption is at $630 \mathrm{~nm}$. A stock solution of brilliant blue, $1000 \mathrm{mg} / \mathrm{L}(1.26 \mathrm{mM})$, was obtained by weighing $1.0 \mathrm{~g}$ of brilliant blue powder in a volumetric flask. Distilled water was added and the solution diluted to the $1000 \mathrm{ml}$ mark. Test solutions were prepared by diluting the stock solution $(1.26 \mathrm{mM})$ to the desired concentration.

\subsubsection{Measurement of the concentrations of food colour solutions}

The standard calibration curves of tartrazine and brilliant blue solutions were plotted by measuring the absorbance, at the characteristic wavelength, for each of the food colours. UV-visible spectrophotometer was used for absorbance measurement. The calibration curve shows a linear variation of absorbance with concentration. Then, concentrations of the supernatant solutions were obtained from the standard calibration curve of each of the food colours. 


\subsection{Preparation of activated carbon}

Activated carbon was prepared from sawdust waste by chemical activation process. The waste was crushed to obtain the desired size fractions (0.5-1.2 mm). The selected fractions of particle size were dried in an oven, at a temperature of $100{ }^{\circ} \mathrm{C}$ for 12 hours, and pulverized to tiny particles, before sieving. The dried precursors were washed with the solution of hydrochloric acid and distilled water, to remove materials adhering to these particles and oven-dried for another 6 hours. Thereafter, the mixture was impregnated with $\mathrm{KOH}$ solution $(1.5 \mathrm{M})$, with an impregnation ratio (w/w) of $4: 1(\mathrm{KOH}$ : char) and soaked for 4 hours. It was then dried, before subjected to carbonization and an activation process, which were carried out concurrently at $550{ }^{\circ} \mathrm{C}$ for 1 hour in a programmable electrical furnace. The activated product was washed extensively with hot distilled water, to remove free acid. The washed activated carbon was dried for 12 hours in an air oven at $100^{\circ} \mathrm{C}$. The samples were then stored in an air-tight container till further use.

\subsection{Adsorption studies}

Batch adsorption studies were employed in this work, and adsorption capacity for the sawdust-based activated carbon (SDAC) was investigated. The equilibrium isotherm uptake of each solution of the food colours was also investigated, in a thermostatic magnetic stirrer, at difference temperatures (308 K, 318 $\mathrm{K}, 328 \mathrm{~K}$ and $338 \mathrm{~K}$ ). In each adsorption experiment, 0.3 $\mathrm{g}$ dose of SDAC, the adsorbent dose for which adsorption was optimum, was added into $30 \mathrm{ml}$ solution of food colour at natural $\mathrm{pH}$ (6.5). The natural $\mathrm{pH}$ value of each solution of food colour was adjusted to a constant value of 6.5 , with dilute $\mathrm{HCl}$ or $\mathrm{NaOH}$, as the case may be, using a $\mathrm{pH}$ meter. The mixtures were stirred on a thermostatic magnetic stirrer for 1 hour, at a particular temperature, for the adsorption process. After shaking the flasks for predetermined time intervals, at selected temperatures, the adsorbateadsorbent samples were withdrawn, and the solutions of food colours separated from SDAC by filtration. The concentrations of the solutions of food colours were determined, using the relevant calibration curves, by measuring absorbance at the required wavelengths. In each case, the amount of food colour adsorbed per unit mass of adsorbent (SDAC) at equilibrium was evaluated, using equation 6 .

$q_{e}=\frac{\left(C_{o}-C_{e}\right) \times V}{M}$

$q_{e}=$ amount of food colour adsorbed per unit mass of adsorbent at equilibrium

$C_{o}=$ initial concentration of the food colour solution

$C_{e}=$ equilibrium concentration of the food colour solution

$V=$ volume of the adsorbate $(0.03 \mathrm{~L})$

$M=$ mass of adsorbent $(0.3 \mathrm{~g})$

\section{RESULTS AND DISCUSSION}

\subsection{Calibration curves of food colours}

Different concentrations of food colours $(2 \mathrm{mg} / \mathrm{L}, 20$ $\mathrm{mg} / \mathrm{L}, 30 \mathrm{mg} / \mathrm{L}, 40 \mathrm{mg} / \mathrm{L}$ and $50 \mathrm{mg} / \mathrm{L}$ ) were prepared from the respective stock solutions. The corresponding absorbance of each of the solution was measured at the characteristic wavelength, while plots of absorbance $(A)$ versus concentration $(C)$ gave the desired calibration curves, shown in Figure 2.

Plots $(A)$ and $(B)$ are the calibration curves for tartrazine and brilliant blue respectively. In each case, absorbance is linearly related to concentration. Unknown concentration of the supernatant solution was determined from the calibration curve of interest.

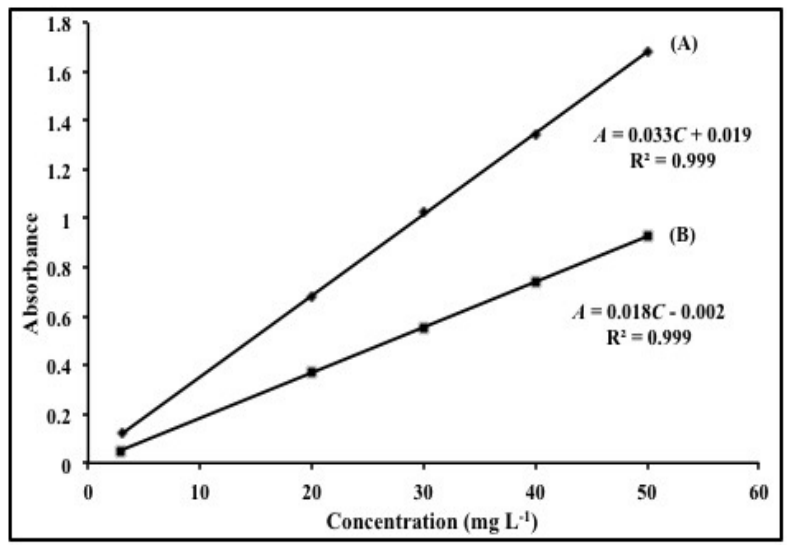

Fig. 2: Calibration curves for (A) Tartrazine and (B) Brilliant blue

\subsection{Adsorption equilibrium studies}

Equilibrium studies were carried out at different temperatures ( $308 \mathrm{~K}, 318 \mathrm{~K}, 328 \mathrm{~K}$ and $338 \mathrm{~K})$, for each of the food colours, with the corresponding Langmuir adsorption constant, $K \mathrm{~L}$, obtained in each case. The Langmuir adsorption model gave the best explanation of the adsorption processes, hence the use of this model for adsorption studies.

\subsubsection{Adsorption equilibrium studies for Tartrazine-SDAC system}

Table 1 shows the results of the equilibrium adsorption studies for tatrazine-SDAC system. The data in table 1 indicate that increase in the initial concentration of adsorbate, $C_{o}$, translates to increase in the amount adsorbed per gram of adsorbent at equilibrium, $q_{\mathrm{e}}$. This is expected, since increased concentration of adsorbate increases its availability to the adsorptive sites on the adsorbent. This provides powerful force to drive mass transfer at the adsorbate-adsorbent interface, hence the increase in the value of $q_{\mathrm{e}}$.

Table 1: Data of adsorption equilibrium studies for Tartrazine-SDAC system

\begin{tabular}{|c|c|c|c|c|c|}
\hline $\mathrm{T}(\mathrm{K})$ & $\begin{array}{l}\text { Initial } \\
\text { Conc. } \\
C_{\circ} \\
\text { (mg/L) }\end{array}$ & $\begin{array}{l}\text { Final } \\
\text { Conc. } \\
C_{\mathrm{e}} \\
\text { (mg/L) }\end{array}$ & $\begin{array}{l}\text { Amount } \\
\text { adsorbed } \\
\text { per } \\
\text { mass }\left(q_{e}\right) \\
(\mathrm{ma} / \mathrm{q})\end{array}$ & $\begin{array}{l}1 / C_{\mathrm{e}} \\
(\mathrm{L} / \mathrm{mg})\end{array}$ & $\begin{array}{l}1 / q_{e} \\
(\mathrm{~g} / \mathrm{mg})\end{array}$ \\
\hline
\end{tabular}




\begin{tabular}{|l|l|l|l|l|l|}
\hline 308 & 10 & 2.68 & 0.732 & 0.373 & 1.366 \\
\hline 308 & 20 & 5.98 & 1.402 & 0.167 & 0.713 \\
\hline 308 & 30 & 10.35 & 1.965 & 0.097 & 0.509 \\
\hline 308 & 40 & 15.24 & 2.476 & 0.066 & 0.404 \\
\hline 308 & 50 & 20.35 & 2.965 & 0.049 & 0.337 \\
\hline & & & & & \\
\hline 318 & 10 & 2.76 & 0.724 & 0.362 & 1.381 \\
\hline 318 & 20 & 6.05 & 1.395 & 0.165 & 0.717 \\
\hline 318 & 30 & 10.44 & 1.956 & 0.096 & 0.511 \\
\hline 318 & 40 & 15.35 & 2.465 & 0.065 & 0.406 \\
\hline 318 & 50 & 20.45 & 2.955 & 0.049 & 0.338 \\
\hline & & & & & \\
\hline 328 & 10 & 3.02 & 0.698 & 0.331 & 1.433 \\
\hline 328 & 20 & 7.01 & 1.299 & 0.143 & 0.770 \\
\hline 328 & 30 & 10.48 & 1.952 & 0.095 & 0.512 \\
\hline 328 & 40 & 16.37 & 2.363 & 0.061 & 0.423 \\
\hline 328 & 50 & 20.48 & 2.952 & 0.049 & 0.339 \\
\hline & & & & & \\
\hline 338 & 10 & 3.10 & 0.690 & 0.323 & 1.449 \\
\hline 338 & 20 & 7.10 & 1.290 & 0.141 & 0.775 \\
\hline 338 & 30 & 10.60 & 1.940 & 0.094 & 0.515 \\
\hline 338 & 40 & 16.49 & 2.351 & 0.061 & 0.425 \\
\hline 338 & 50 & 20.60 & 2.940 & 0.049 & 0.340 \\
\hline
\end{tabular}

$\frac{1}{q_{e}}=\frac{3.295}{c_{e}}+0.184$

From equation 8 , the intercept, $1 / q_{0}$, and slope, $1 / K_{\llcorner} q_{0}$, of the plot at $318 \mathrm{~K}$ are 0.184 and 3.295 , respectively. These give a Langmuir constant of adsorption, $K \mathrm{~L}$, of $5.58 \times 10^{-2} \mathrm{~L} \mathrm{mg}^{-1}$ for the tartrazine-SDAC system at 318 $\mathrm{K}$.

From the plots in Figure 3, the Langmuir isotherm equations for the tartrazine-SDAC system at $328 \mathrm{~K}$ and $338 \mathrm{~K}$ are defined by equations 9 and 10 , respectively.

$\frac{1}{q_{e}}=\frac{3.839}{C_{e}}+0.174$

$\frac{1}{q_{e}}=\frac{4.009}{C_{e}}+0.165$

From equations 9 and 10, the Langmuir constants of adsorption at $328 \mathrm{~K}$ and $338 \mathrm{~K}$, for the tartrazine-SDAC system, are $4.53 \times 10^{-2} \mathrm{~L} \mathrm{mg}^{-1}$ and $4.11 \times 10^{-2} \mathrm{~L} \mathrm{mg}^{-1}$, respectively.

The thermodynamic quantities $(\Delta H, \Delta S$ and $\Delta G)$, table 2 , associated with the tartrazine-SDAC system were determined from the information obtainable from the plot of In $K_{\mathrm{L}}$ versus $1 / T$ (Figure 4). From the plot in Figure 4 , the relationship between $\ln K_{\mathrm{L}}$ and $1 / T$ is defined by equation 11

$\ln K_{L}=\frac{1458}{T}-7.514$

The results in table 1 also show that the amount of adsorbate adsorbed per gram of adsorbent at equilibrium, $q_{\mathrm{e}}$, decreases as temperature increases. This suggests that the adsorption process at the tartrazine-SDAC interface may be exothermic.

Plots of $\frac{1}{q_{e}}$ against $\frac{1}{c_{e}}$ for the tartrazine-SDAC system, at different temperatures, are straight lines (Figure 3). From the plots in Figure 3, the Langmuir isotherm equation at $308 \mathrm{~K}$ is given by equation 7 .

$\frac{1}{q_{e}}=\frac{3.145}{c_{e}}+0.192$

7

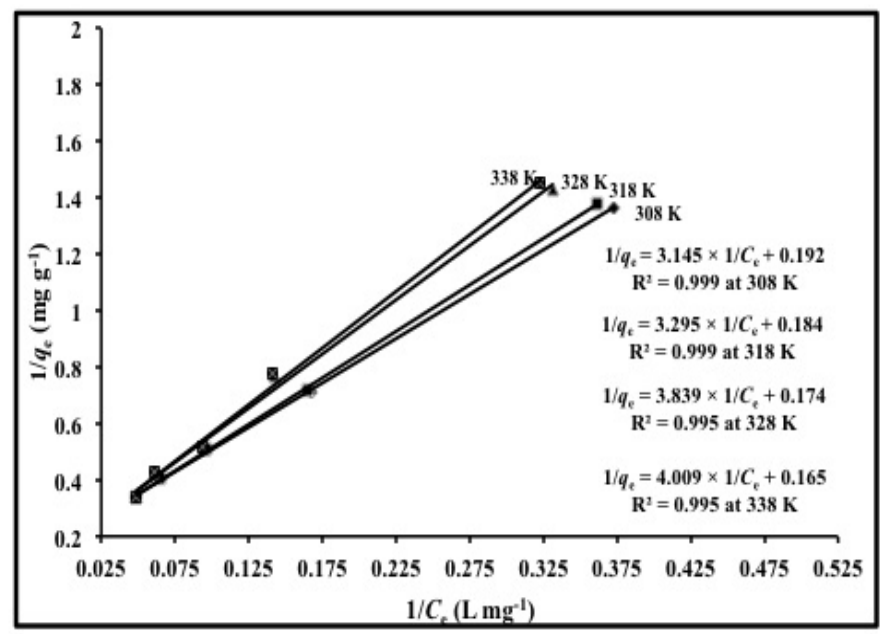

Fig. 3: Plots of $1 / q_{\mathrm{e}}$ versus $1 / C_{\mathrm{e}}$ for Tartrazine-SDAC system at different temperatures

Comparison of equation 7 with equation 2, shows that the intercept, $1 / q_{0}$, and slope, $1 / K_{\llcorner} q_{0}$, of the plot at 308 $\mathrm{K}$ are 0.192 and 3.145 respectively. These give a Langmuir constant of adsorption, $K_{\mathrm{L}}$, of $6.10 \times 10^{-2} \mathrm{~L} \mathrm{mg}^{-}$ 1 for the tartrazine-SDAC system at this temperature. From the plots in Figure 3, the Langmuir isotherm equation at $318 \mathrm{~K}$, for the tartrazine-SDAC system, is given by equation 8 .

Table 2: Thermodynamic parameters of adsorption at the Tartrazine-SDAC interface

\begin{tabular}{|l|l|l|l|l|l|l|}
\hline $\begin{array}{l}\mathrm{T} \\
(\mathrm{K})\end{array}$ & $\begin{array}{l}K_{\mathrm{L}} \\
(\mathrm{L} / \mathrm{mg})\end{array}$ & $\begin{array}{l}\mathrm{In} K_{\mathrm{L}} \\
(\mathrm{L} / \mathrm{mg})\end{array}$ & $\begin{array}{c}1 / T \\
\left(\mathrm{~K}^{-1}\right)\end{array}$ & $\begin{array}{c}\Delta H \\
\mathrm{KJ}^{-1} \\
\mathrm{~mol}^{-1}\end{array}$ & $\begin{array}{l}\Delta S \\
\mathrm{Kol}^{-1}\end{array}$ & $\begin{array}{l}\Delta G \\
\mathrm{~kJ} \\
\mathrm{~mol}^{-1}\end{array}$ \\
\hline 308 & $\begin{array}{l}6.12 \\
\times 10^{-2}\end{array}$ & -2.794 & $\begin{array}{l}3.247 \\
\times 10^{-3}\end{array}$ & -12.12 & -62.47 & +7.12 \\
\hline 318 & $\begin{array}{l}5.58 \\
\times 10^{-2}\end{array}$ & -2.886 & $\begin{array}{l}3.145 \\
\times 10^{-3}\end{array}$ & -12.12 & -62.47 & +7.75 \\
\hline 328 & $\begin{array}{l}4.53 \\
\times 10^{-2}\end{array}$ & -3.094 & $\begin{array}{l}3.049 \\
\times 10^{-3}\end{array}$ & -12.12 & -62.47 & +8.37 \\
\hline 338 & $\begin{array}{l}4.11 \\
\times 10^{-2}\end{array}$ & -3.192 & $\begin{array}{l}2.959 \\
\times 10^{-3}\end{array}$ & -12.12 & -62.47 & +9.00 \\
\hline
\end{tabular}

Comparison of equation 11 with equation 5 (the Van't Hoff equation) indicates that the slope, $-\Delta H / R$, and intercept, $\Delta S / R$, of the plot in Figure 4 are 1458 and 7.514 , respectively. The quantity $R$ is molar gas constant $\left(8.314 \mathrm{~J} \mathrm{~K}^{-1} \mathrm{~mol}^{-1}\right)$. The value of $\Delta H$ obtained from the slope is $-12.12 \mathrm{~kJ} \mathrm{~mol}^{-1}$. This is consistent with the trend observed in table I and the earlier submission that the process of adsorption at the tartrazine-SDAC interface may be exothermic. The value of $\Delta S$, obtained from the intercept of the plot, is $-62.47 \mathrm{~J} \mathrm{~K}^{-1} \mathrm{~mol}^{-1}$. This suggests a decreasing degree of randomness at the tartrazine-SDAC interface, and low adsorbateadsorbent interaction. The values of $\Delta G$ were obtained using the relationship in equation $4(\Delta G=\Delta H-T \Delta S)$. Positive values of $\Delta G$ (table 2) show that the adsorption of tartrazine onto SDAC is non- spontaneous and thermodynamically unfavourable at the temperature range employed in this work. 


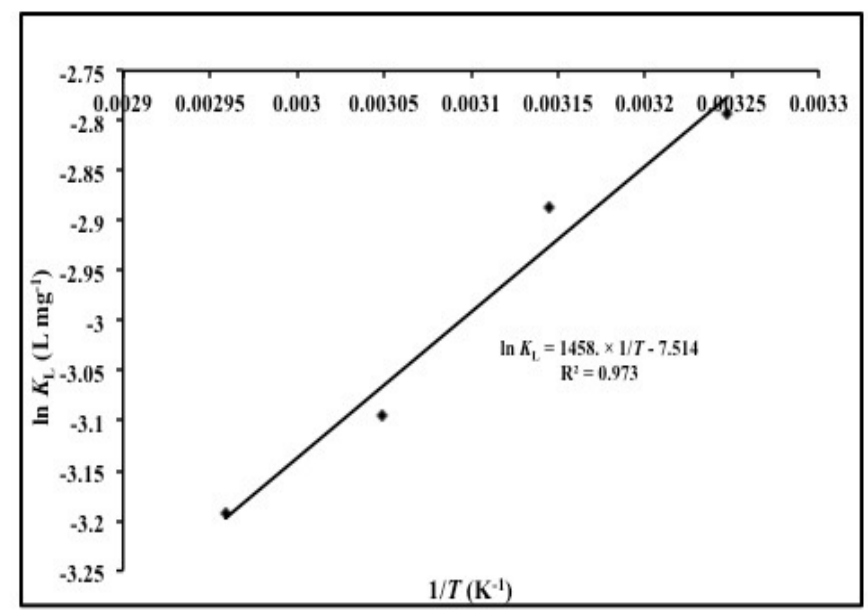

Fig. 4: Plot of In $K_{\mathrm{L}}$ versus $1 / T$ for Tartrazine-SDAC system

Using equation 4 , values of $\Delta H$ and $\Delta S$ in table II suggest that, at sufficiently low temperature, negative value of $\Delta G$ can be obtained for the adsorption of tartrazine at the tartrazine-SDAC interface. This implies that removal of tartrazine from food products, using SDAC, may be more effective at reasonably lower temperature than the range employed in this work.

\subsubsection{Adsorption equilibrium studies for Brilliant blue-SDAC system}

The results of the equilibrium adsorption studies for brilliant blue-SDAC system are shown in table 3 . The data in table 3 show that, at room temperature $\left(35^{\circ} \mathrm{C}\right.$ or $308 \mathrm{~K}$ ), for each value of initial concentration, relatively lower amount of adsorbate was adsorbed per gram of adsorbent at equilibrium, compared to the amount adsorbed in the tartrazine-SDAC system (table 1). This trend may be closely related to the difference in molecular sizes of these food colours (Figure 1). The molecular size of tartrazine is smaller than that of brilliant blue. Hence, at room temperature, the essentially meso-macroporous SDAC network is better suited to adsorb higher amount of tartrazine than brilliant blue. It is suffice to say that, at room temperature, the adsorption of brilliant blue may be enhanced by using an adsorbent with predominantly macroporous network, unlike the meso-macroporous SDAC used in the current work.

Another very significant observation from the comparison of the results in tables 1 and 3 is the effect of temperature on the adsorption process. In table 3 , unlike the tartrazine-SDAC system (table 1), the amount of adsorbate adsorbed per gram of adsorbent, at equilibrium, increases with increasing temperature.

This suggests that adsorption at the brilliant blue-SDAC interface may be an endothermic process. Increase in temperature may have resulted in increase in pore size of the adsorbent, which favoured the adsorption of relatively higher amount of brilliant blue.
Table 3: Data of adsorption equilibrium studies for Brilliant blue-SDAC system

\begin{tabular}{|c|c|c|c|c|c|}
\hline $\mathrm{T}(\mathrm{K})$ & $\begin{array}{l}\text { Initial } \\
\text { Conc. } \\
C_{\circ} \\
(\mathrm{mg} / \mathrm{L})\end{array}$ & $\begin{array}{l}\text { Final } \\
\text { Conc. } \\
C_{\mathrm{e}} \\
(\mathrm{mg} / \mathrm{L})\end{array}$ & $\begin{array}{l}\text { Amount } \\
\text { adsorbed } \\
\text { per mass } \\
\left(q_{\mathrm{e}}\right) \\
(\mathrm{mg} / \mathrm{g})\end{array}$ & $\begin{array}{l}1 / C_{\mathrm{e}} \\
(\mathrm{L} / \mathrm{mg})\end{array}$ & $\begin{array}{l}1 / q_{\mathrm{e}} \\
(\mathrm{g} / \mathrm{mg})\end{array}$ \\
\hline 308 & 10 & 3.46 & 0.654 & 0.289 & 1.529 \\
\hline 308 & 20 & 6.92 & 1.308 & 0.145 & 0.765 \\
\hline 308 & 30 & 10.86 & 1.914 & 0.092 & 0.522 \\
\hline 308 & 40 & 15.88 & 2.412 & 0.063 & 0.415 \\
\hline 308 & 50 & 20.85 & 2.915 & 0.048 & 0.343 \\
\hline & & & & & \\
\hline 318 & 10 & 3.04 & 0.696 & 0.329 & 1.437 \\
\hline 318 & 20 & 6.08 & 1.392 & 0.164 & 0.718 \\
\hline 318 & 30 & 9.51 & 2.049 & 0.105 & 0.488 \\
\hline 318 & 40 & 13.88 & 2.612 & 0.072 & 0.383 \\
\hline 318 & 50 & 19.20 & 3.080 & 0.052 & 0.325 \\
\hline & & & & & \\
\hline 328 & 10 & 2.47 & 0.753 & 0.405 & 1.328 \\
\hline 328 & 20 & 4.94 & 1.506 & 0.202 & 0.664 \\
\hline 328 & 30 & 7.71 & 2.229 & 0.130 & 0.449 \\
\hline 328 & 40 & 11.56 & 2.844 & 0.087 & 0.352 \\
\hline 328 & 50 & 15.75 & 3.425 & 0.063 & 0.292 \\
\hline & & & & & \\
\hline 338 & 10 & 1.65 & 0.835 & 0.599 & 1.198 \\
\hline 338 & 20 & 3.30 & 1.670 & 0.303 & 0.599 \\
\hline 338 & 30 & 5.50 & 2.450 & 0.182 & 0.408 \\
\hline 338 & 40 & 7.92 & 3.208 & 0.126 & 0.312 \\
\hline 338 & 50 & 11.10 & 3.890 & 0.090 & 0.257 \\
\hline
\end{tabular}

This is consistent with our earlier submission, that adsorption of brilliant blue may be enhanced on adsorbent with relatively larger pore size than the one employed in this work.

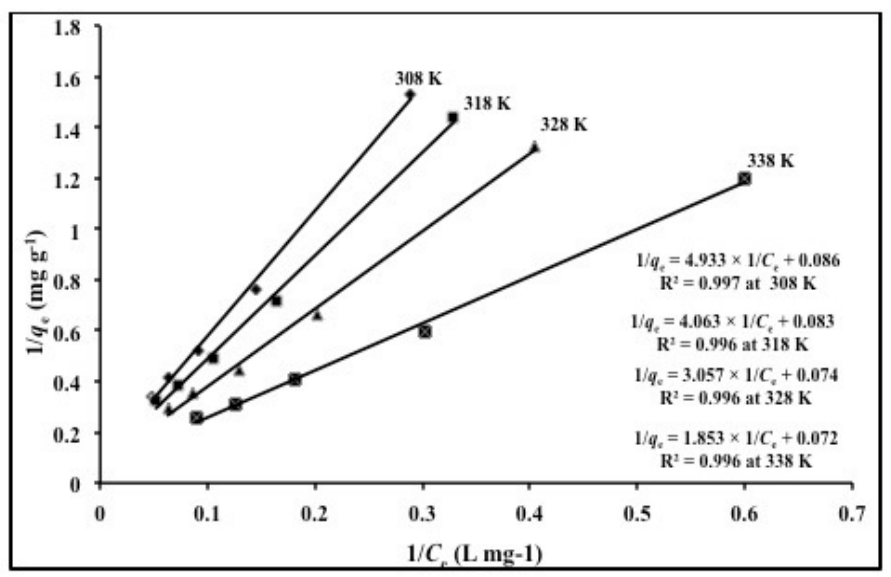

Fig. 5: Plots of $1 / q_{\mathrm{e}}$ versus $1 / C_{\mathrm{e}}$ for Brilliant blueSDAC system at different temperatures

Plots of $\frac{1}{q_{e}}$ against $\frac{1}{c_{e}}$ for the brilliant blue-SDAC system, at different temperatures, are straight lines, Figure 5. From the plots in Figure 5, the Langmuir isotherm equation at $308 \mathrm{~K}, 318 \mathrm{~K}, 328 \mathrm{~K}$ and $338 \mathrm{~K}$ are given by equations $12,13,14$ and 15 , respectively.

$\frac{1}{q_{e}}=\frac{4.933}{C_{e}}+0.086$
$\frac{1}{q_{e}}=\frac{4.063}{C_{e}}+0.083$ 
$\frac{1}{q_{e}}=\frac{3.057}{C_{e}}+0.074$

$\frac{1}{q_{e}}=\frac{1.853}{C_{e}}+0.072$

As discussed previously for the tartrazine-SDAC system, the Langmuir constants of adsorption for the brilliant blue-SDAC system were calculated from the intercepts and slopes of the plots in Figure 5 . The values of Langmuir constants at $308 \mathrm{~K}, 318 \mathrm{~K}, 328 \mathrm{~K}$ and $338 \mathrm{~K}$ are $1.73 \times 10^{-2}, 2.04 \times 10^{-2}, 2.42 \times 10^{-2}$ and $3.89 \times 10^{-2} \mathrm{~L} \mathrm{mg}^{-1}$, respectively (table 4). Like the tartrazine-SDAC system, thermodynamic parameters (table 4) of the brilliant blue-SDAC system were determined from the information obtainable from the plot of In $K_{\mathrm{L}}$ versus $1 / T$ (Figure 6 ). From the plot in Figure 6 , the relationship between $\ln K \mathrm{~L}$ and $1 / T$ is defined by equation 16

$\ln K_{L}=-\frac{2687}{T}+4.60$

Table 4: Thermodynamic parameters of adsorption at the Brilliant blue-SDAC interface

\begin{tabular}{|l|l|l|l|l|l|l|}
\hline $\begin{array}{l}\mathrm{T} \\
(\mathrm{K})\end{array}$ & $\begin{array}{l}\mathrm{K} \\
(\mathrm{L} / \mathrm{mg})\end{array}$ & $\begin{array}{l}\mathrm{In} \mathrm{K}_{\mathrm{L}} \\
(\mathrm{L} / \mathrm{mg})\end{array}$ & $\begin{array}{c}1 / T \\
\left(\mathrm{~K}^{-1}\right)\end{array}$ & $\begin{array}{l}\Delta H \\
\mathrm{~kJ} \\
\mathrm{~mol}^{-1}\end{array}$ & $\begin{array}{l}\Delta S \\
\mathrm{Jol}^{-1}\end{array}$ & $\begin{array}{c}\Delta G \\
\mathrm{~kJ} \mathrm{~mol}^{-1}\end{array}$ \\
\hline 308 & $\begin{array}{l}1.73 \\
\times 10^{-2}\end{array}$ & -4.057 & $\begin{array}{l}3.247 \\
\times 10^{-3}\end{array}$ & +22.34 & +38.24 & +10.56 \\
\hline 318 & $\begin{array}{l}2.04 \\
\times 10^{-2}\end{array}$ & -3.892 & $\begin{array}{l}3.145 \\
\times 10^{-3}\end{array}$ & +22.34 & +38.24 & +10.18 \\
\hline 328 & $\begin{array}{l}2.42 \\
\times 10^{-2}\end{array}$ & -3.721 & $\begin{array}{l}3.049 \\
\times 10^{-3}\end{array}$ & +22.34 & +38.24 & +9.80 \\
\hline 338 & $\begin{array}{l}3.89 \\
\times 10^{-2}\end{array}$ & -3.247 & $\begin{array}{l}2.959 \\
\times 10^{-3}\end{array}$ & +22.34 & +38.24 & +9.41 \\
\hline
\end{tabular}

Like equation 11, equation 16 is a version of the Van't Hoff equation (equation 5). Therefore, the slope, $-\Delta H / R$, and intercept, $\Delta S / R$, of the plot in Figure 6 are -2687 and +4.60 , respectively. $R\left(8.314 \mathrm{~J} \mathrm{~K}^{-1} \mathrm{~mol}^{-1}\right)$ is as defined previously. The value of $\Delta H$ calculated from the slope is $+22.34 \mathrm{~kJ} \mathrm{~mol}^{-1}$. This is consistent with our previous submission that adsorption at the brilliant blueSDAC interface may be an endothermic process. The value of $\Delta S$ calculated from the intercept is $+38.24 \mathrm{~J} \mathrm{~K}^{-}$ $1 \mathrm{~mol}^{-1}$, which suggest a relatively high degree of disorderliness at the brilliant blue-SDAC interface, and substantial adsorbent-adsorbate interaction. The values of $\Delta H$ and $\Delta S$ show that adsorption of brilliant-blue onto SDAC is a high energy process. This implies that significant amount of this food colour may be removed, in case it is used in excess of its recommended value or triggers adverse health effects in food products, if the adsorption process is carried out at higher temperature than the range employed in this work.

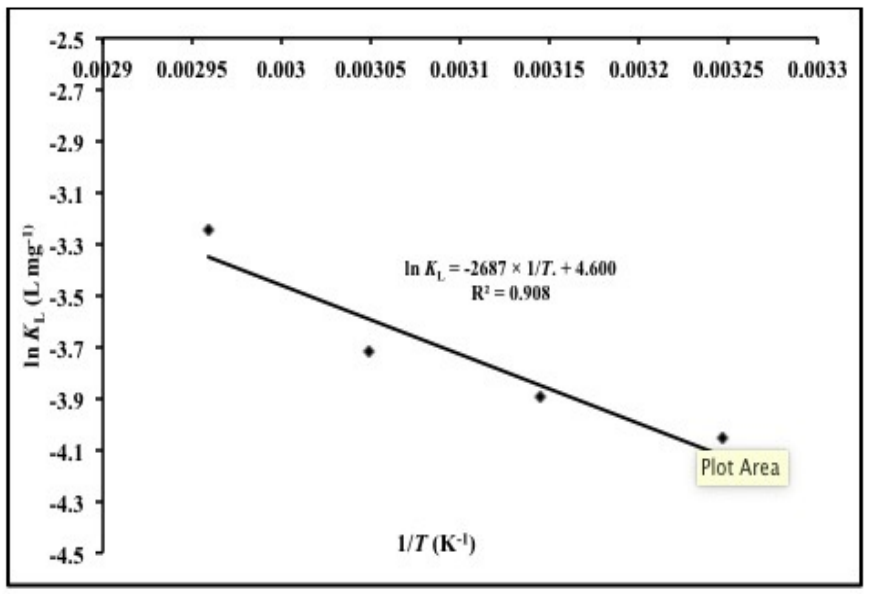

Fig. 6: Plot of In $K_{\mathrm{L}}$ versus $1 / T$ for Brilliant blueSDAC system

Values of $\Delta G$ were obtained using the relationship in equation $4(\Delta G=\Delta H-T \Delta S)$. Positive values of $\Delta G$ (table 4) show that the adsorption of brilliant blue onto SDAC is non- spontaneous and thermodynamically unfavourable at the temperature range employed in this work. Since the process has positive values of $\Delta H$ and $\Delta S$ (table 4 ), it implies that a negative $\Delta G$, and the likelihood of a more effective adsorption process, can be achieved at a sufficiently higher temperature than the range employed in this work.

\section{CONCLUSION}

Thermodynamics of adsorption of two synthetic food colours, tartrazine and brilliant blue, was studied. The food colours were adsorbed onto activated carbon, produced from sawdust waste. The amount of colour adsorbed per gram of adsorbate at equilibrium was influenced by the molecular size of the colour of interest and temperature. The colour with smaller molecular size, tartrazine, was adsorbed better at lower temperature than the colour with larger molecular size, brilliant blue. Thermodynamic parameters (change in enthalpy, $\Delta H$, and entropy change, $\Delta S$ ) were closely related to the molecular size of the synthetic colour of interest. Adsorption at the tartrazine-adsorbent interface was exothermic, while that at the brilliant blueadsorbent system was endothermic. Adsorption of tartrazine has negative $\Delta S$, while that of brilliant blue was associated with positive $\Delta S$. The change in Gibbs free energy, $\Delta G$, was positive for each of the adsorbateadsorbent systems, suggesting the adsorption processes were not thermodynamically favourable, within the range of temperature investigated. However, at lower temperature range than that employed in this work, the tartrazine-adsorbent system may be effective in removing tartrazine from food products. For brilliant blue, its removal from food products may be encouraged, at a higher temperature range than the one used in this work. 


\section{REFERENCES}

1. Delwiche J. The impact of perceptual interactions on perceived flavor. Food Quality Preference. 2004; (15):137-46

2. AbdEI-Galeel MA. Solubility and stability of natural food colourants in microemulsions. Rheinschen Friedrich-Wilhelms Universital Zu Bonn; 2002

3. Henry JB. Natural Food Colours in Natural Food Colourants. Chapman and Hull, U.K. $2^{\text {nd }}$ Edition, ISBN10; 1996

4. Food and Drug Administration, Summary of Colour additives for use in United States in foods, drugs, cosmetics and medical devices; 2007

5. Hattis D. Age-related differences in susceptibility to carcinogenesis II; Approaches for application and uncertainty analysis for individual genetically acting carcinogens. Environmental Health Perspective. 2005; (113):509-16

6. Collins WC. Clinical spectrum of adverse reactions to tartrazine. J. Asthma. 1985; (22):139-43
7. Lau K. Synergestic interactions between commonly used food additives in a developmental neurotoxicity test. Toxicology Sciences. 2006; (90(1)):178-87

8. Cameron carbon incorporated e-book: activated carbon; 2012

9. Nevine KA. 2008. Removal of reactive dye from aqueous solutions by adsorption onto activated carbon prepared from sugarcane bagasse pith. Desalination. 2008; (223):152-58

10. Monika J, Gargand V, Kadirvelu K. Adsorptive remediation of $\mathrm{Cu}$ (II) and $\mathrm{Ni}$ (II) by microwave activated carbon. J. Hazard Matter. 2009; (162):365-72

11. Li YJ. Adsorption of chromium (VI) from aqueous solution by activated carbon. J. Hazard Matter. 2009; (169):1098-105 